\title{
A survey of Canadian surgeons on the indications for home care nursing following vascular surgery
}

\author{
Jean Jacob-Brassard, MD \\ Mohammed Al-Omran, MD, \\ MSc \\ Konrad Salata, MD, PhD \\ Mohamad A. Hussain, MD, \\ $\mathrm{PhD}$ \\ Ahmed Kayssi, MD, MPH \\ Graham Roche-Nagle, MD, \\ MBA \\ Charles de Mestral, MDCM, \\ $\mathrm{PhD}$
}

This work was presented at the University of Toronto Annual Research Day on June 21, 2019 in Toronto, Ont., and at the $19^{\circ}$ Congrès annuel de la SSVq in Québec, Que., on November 21, 2019.

Accepted April 18, 2020

Correspondence to:

C. de Mestral

St Michael's Hospital

30 Bond Street

Office Bond 7-080

Toronto ON M5B 1W8

charles.deMestral@unityhealth.to

DOI: $10.1503 /$ cjs.001220
Background: Recent evidence suggests that home care nursing is variably prescribed after vascular surgery, and may reduce emergency department visits and hospital readmissions. We therefore sought to characterize the indications for home care nursing following vascular surgery from the surgeon's perspective.

Methods: An online survey was distributed to the 141 members of the Canadian Society for Vascular Surgery with questions related to home care nursing after carotid endarterectomy (CEA), endovascular aortic aneurysm repair (EVAR), open abdominal aortic aneurysm (AAA) repair and open or hybrid revascularization for peripheral arterial disease (PAD). We included all questionnaires in our analysis; the frequency denominator changes according to the number of respondents who completed each survey item.

Results: There were 46 survey respondents (33\% of 141) from across the country. A total of $28(62 \%$ of 45$)$ worked in a teaching hospital. Home care nursing was routinely prescribed by $5 \%, 10 \%, 31 \%$ and $41 \%$ of respondents following CEA, EVAR, open AAA repair and open or hybrid revascularization for $\mathrm{PAD}$, respectively. Across all procedure types, the same procedure-related criteria were most often deemed to warrant a prescription for home care nursing: surgical site infection, wound complications (e.g., open wound, lymphatic leak) and use of negative-pressure wound therapy. Across all procedure types, lack of social support, physical frailty and cognitive impairment were most frequently identified as patient-specific considerations for prescribing home care nursing. Few respondents reported restrictions or standards that informed their prescribing practice.

Conclusion: Most surgeon respondents agreed on the indications for home care nursing after vascular surgery. However, evidence-based standards to guide patient selection for home care nursing after vascular surgery are needed.

Contexte : Selon des données récentes, les soins infirmiers à domicile sont prescrits aléatoirement après la chirurgie vasculaire, et pourraient réduire les consultations aux urgences et les réhospitalisations. Nous avons donc voulu caractériser les indications des soins infirmiers à domicile après la chirurgie vasculaire, du point de vue des chirurgiens.

Méthodes : Nous avons transmis un sondage en ligne aux 141 membres de la Société canadienne de chirurgie vasculaire (SCCV); les questions portaient sur les soins infirmiers à domicile après l'endartériectomie carotidienne, la réparation endovasculaire de l'anévrisme de l'aorte, la réparation chirurgicale de l'anévrisme de l'aorte abdominale (AAA) et la revascularisation chirurgicale ou hybride de la maladie artérielle périphérique (MAP). Nous avons inclus tous les questionnaires dans notre analyse; le dénominateur de fréquence change en fonction du nombre de répondants qui ont répondu à chaque élément du sondage.

Résultats : Quarante-six chirurgiens des quatre coins du pays ont répondu (33\% des 141 membres de la SCCV). En tout, 28 (62\% des of 45) travaillaient dans un établissement universitaire. Les soins infirmiers à domicile étaient prescrits d'emblée par $5 \%$, $10 \%, 31 \%$ et $41 \%$ des répondants suite à l'endartériectomie carotidienne, la réparation endovasculaire de l'anévrisme de l'aorte, la chirurgie pour AAA et la revascularisation chirurgicale ou hybride de la MPA, respectivement. Pour tous les types d'interventions, les mêmes critères liés aux interventions ont semblé justifier la prescription de soins infirmiers à domicile : infection de plaie, complications au niveau de la plaie (p. ex., plaie ouverte, plaie exsudative) et traitement de plaie par pression négative. Pour tous les types d'intervention, l'absence de soutien social, la fragilité physique et le déclin cognitif ont le plus souvent été identifiés parmi les critères spécifiques aux patients pour la prescription de soins infirmiers à domicile. Peu de répondants ont mentionné de possibles restrictions ou normes sur lesquelles fonder leurs habitudes de prescription à ce chapitre.

Conclusion : La plupart des chirurgiens participants se sont entendus sur les indications des soins infirmiers à domicile après la chirurgie vasculaire. Il faudrait toutefois établir des normes fondées sur des données probantes pour guider la sélection des patients candidats aux soins infirmiers à domicile après la chirurgie vasculaire. 
W hen patients are discharged from hospital after surgery, home care support can be provided to optimize their recovery at home. ${ }^{1}$ In a recent study of vascular surgery quality outcomes and costs within a single-payer health care system, home care services constituted an important proportion of health care cost within 30 days of discharge, second only to hospital readmission. ${ }^{2}$ A follow-up study of nursing care showed that receiving home care nursing (at home or in the community) was associated with a lower risk of hospital readmission or an emergency department visit within 30 days of discharge. ${ }^{3}$ However, home care nursing was inconsistently prescribed. ${ }^{3}$ Data on the use and effect of home care nursing after vascular or other surgeries remain sparse. Furthermore, the perceived indications for home care nursing among vascular surgeons remain uncertain. Given these considerations, our objective was to characterize the surgeon's perspective on current indications for discharging patients with home care nursing after vascular surgery.

\section{Methods}

\section{Study design}

We conducted a survey of Canadian vascular surgeons to understand their prescribing practice with respect to home care nursing, in accordance with the Checklist for Reporting Results of Internet E-Surveys. ${ }^{4}$ We created the survey using the SurveyMonkey platform. It contained 31 multiple choice questions spread over 9 pages (with 1-6 items per page). Two authors tested the survey for ease of use and feasibility before submission. Potential respondents had the opportunity to change their answers throughout the survey by using the back button. We disabled multiple responses per Internet Protocol (IP) address to limit the number of multiple entries per individual. No personal information was collected or stored.

Respondents first identified their region of practice and hospital teaching status. A teaching hospital was defined as having residents or fellows rotating on the vascular surgery service at least $20 \%$ of the year. Respondents were then asked about their practice regarding discharge with home care nursing (at home or in the community) after 4 vascular procedures: carotid endarterectomy (CEA), open abdominal aortic aneurysm (AAA) repair, endovascular aneurysm repair (EVAR) and open or hybrid revascularization procedures for peripheral arterial disease (PAD). More specifically, they were asked about availability of home care nursing, defined as the possibility to prescribe it, if deemed necessary; pre-established local restrictions or standardized indications that dictate when home care can be prescribed within their institution or geographical area; and their perspective on procedure- and patient-specific criteria whereby a patient would benefit from home care nursing. Procedure-specific criteria related to any charac- teristic or complication of the procedure. Patient-specific criteria included patient characteristics (e.g., comorbidities, social status). Most procedure- and patient-specific criteria applied to all 4 major vascular procedures, with some exceptions that were specific to a single surgery type. For example, "complication of common femoral puncture" is a criterion that does not apply to carotid endarterectomy.

The online survey (Appendix 1, available at canjsurg. ca/001220-a1) was distributed to the 141 members of the Canadian Society for Vascular Surgery via its member email distribution list. An electronic informed consent form (Appendix 1) was provided along with the survey. We closed the survey after 1 month and 2 reminders. Survey responses were recorded by SurveyMonkey. Ethics approval for this study was granted by the Research Ethics Board of Unity Health Toronto.

\section{Statistical analysis}

The results were expressed in aggregate for all respondents and compared across procedure type, region and teaching status of the hospital (teaching v. nonteaching). We used Fisher exact tests for univariate comparisons, and we considered a 2 -tailed $p$ value $<0.05$ the threshold for statistical significance. We included all questionnaires, even incomplete ones, in our analysis; the frequency denominator changes according to the number of respondents who completed each survey item.

\section{Results}

The survey response rate was $33 \%$ (46/141). Its completion rate was $89 \%$ (41/46). Responses originated from all regions of Canada: $35 \%$ (16/46) were from Ontario, 22\% $(10 / 46)$ were from the Prairies (Alberta, Saskatchewan and Manitoba), 15\% (7/46) were from British Columbia, 15\% (7/46) were from Quebec and 13\% (6/46) were from Atlantic Canada (New Brunswick, Nova Scotia and Newfoundland and Labrador). A total of $62 \%$ (28/45) of respondents worked in a teaching hospital.

\section{Availability, routine prescription and standardized indications for home care nursing}

The reported availability, prescription and indications for home care nursing are shown in Table 1. Home care nursing was reported to be available by most respondents for CEA and EVAR, and by all respondents for open AAA repair and open or hybrid revascularization for PAD. When comparing specific nursing services across procedure types, wound care was available to all respondents after open or hybrid revascularization for PAD but not always for other procedures. If home care nursing was prescribed, the proportion of respondents making the referral themselves (as opposed to delegate 


\begin{tabular}{|c|c|c|c|c|c|}
\hline \multirow[b]{2}{*}{ Variable } & \multicolumn{4}{|c|}{ No. (\%) of respondents } & \multirow[b]{2}{*}{$p$ value } \\
\hline & $\begin{array}{c}\text { CEA } \\
n=43^{*}\end{array}$ & $\begin{array}{c}\text { EVAR } \\
n=41^{*}\end{array}$ & $\begin{array}{c}\text { AAA } \\
n=42^{*}\end{array}$ & $\begin{array}{l}\text { PAD } \\
n=41\end{array}$ & \\
\hline \multicolumn{6}{|l|}{ Availability } \\
\hline Home care nursing available & $38(88)$ & $37(90)$ & $42(100)$ & $41(100)$ & 0.011 \\
\hline \multicolumn{6}{|l|}{ Specific home care nursing service available } \\
\hline Wound care & $34(79)$ & $34(83)$ & 39 (93) & $41(100)$ & 0.004 \\
\hline \multicolumn{6}{|l|}{ Indication } \\
\hline Suture or staple removal & $25(58)$ & $28(68)$ & $33(79)$ & $30(73)$ & 0.209 \\
\hline Drain check or removal & $13(30)$ & $12(29)$ & $18(43)$ & $21(51)$ & 0.118 \\
\hline Intravenous medications & $18(42)$ & $18(44)$ & $21(50)$ & $22(54)$ & 0.685 \\
\hline Routine postoperative check & $10(23)$ & $9(22)$ & $11(26)$ & $8(20)$ & 0.908 \\
\hline Routinely prescribe home care nursing & $2(5)$ & $4(10)$ & $13(31)$ & $17(41)$ & $<0.001$ \\
\hline $\begin{array}{l}\text { Presence of restrictions or standardized } \\
\text { indications }\end{array}$ & $4(10)$ & $4(10)$ & $4(10)$ & $5(12)$ & 0.977 \\
\hline $\begin{array}{l}\text { Surgeon (rather than delegate) responsible for } \\
\text { prescribing home care nursing }\end{array}$ & $16(41)$ & $15(39)$ & $17(41)$ & $24(59)$ & 0.267 \\
\hline \multicolumn{6}{|c|}{$\begin{array}{l}\text { AAA = Open abdominal aortic aneurysm repair; CEA = Carotid endarterectomy; EVAR: Endovascular abdominal aortic aneurysm repair; PAD: Open or hyb } \\
\text { lower extremity revascularization for peripheral arterial disease. } \\
\text { *Except "Routinely prescribe home care nursing" ( } n=42 \text { for CEA, } n=40 \text { for EVAR, } n=41 \text { for AAA) and "Surgeon (rather than delegate) responsible for } \\
\text { prescribing home care nursing" ( } n=39 \text { for CEA, } n=38 \text { for EVAR, } n=41 \text { for AAA). }\end{array}$} \\
\hline
\end{tabular}

such as a nurse practitioner or resident) was similar across procedure types. Home care nursing was routinely prescribed more frequently after open AAA repair and open or hybrid revascularization for PAD than CEA and EVAR. Restrictions or standardized indications for home care nursing were reported by a minority of respondents for all surgery types. None of the respondents who provided free-text comments suggested their practice was informed by any regional guidelines or procedurespecific restrictions. The comments centred around 3 main points: limited frequency of visits (e.g., "dressing change no more than once a day"), limited scope of services (e.g., "outpatient nursing care must provide a specific medical task and will not do routine care, such as removing staples") and specified location of service (e.g., "most patients are now told to go to a clinic instead of the nurse coming to the home").

\section{Procedure- and patient-specific indications for home care nursing}

The most frequently cited, procedure-specific indications for home care nursing were surgical site infection $(25 / 42$, $60 \%)$, outpatient negative-pressure wound therapy $(18 / 42$, $43 \%)$ and urinary catheter check or removal $(16 / 42,38 \%)$ for CEA; surgical site infection (32/41, 78\%), lymphatic leak $(31 / 41,76 \%)$ and an open wound $(27 / 41,66 \%)$ for EVAR; an open wound $(36 / 42,86 \%)$, surgical site infection $(33 / 42,79 \%)$ and outpatient negative-pressure wound therapy $(32 / 42,76 \%)$ for open AAA repair; and surgical site infection, $(36 / 41,88 \%)$, lymph leak $(36 / 41$, $88 \%)$ and an open wound $(36 / 41,88 \%)$ for open or hybrid revascularization for PAD (Figure 1).
The most frequently cited patient-specific indications for home care nursing were the same for the 4 vascular procedures: lack of social support $(60 \%-$ $71 \%)$, physical frailty $(49 \%-73 \%)$ and dementia or other cognitive impairment $(40 \%-54 \%)$. There were no statistically significant differences observed between procedures (Figure 2).

\section{Regional variation}

Home care nursing was deemed to be similarly available across all regions, with the exception of home care nursing for administration of intravenous medication (Appendix 1, Tables S1, S2, S3 and S4). Furthermore, tendency to routinely prescribe home care nursing, and presence of restriction or standardized indications, did not vary significantly across region. Finally, there were no significant differences when regions were compared for patient-specific indications.

\section{Variation by teaching status of the hospital}

Comparing responses from respondents at teaching hospitals to those from community hospitals, there were no significant differences in home care nursing availability or tendency to routinely prescribe home care nursing (Appendix 1, Tables S5, S6, S7 and S8). The proportion of respondents indicating the presence of restrictions or standardized indications for home care nursing did not vary significantly by hospital teaching status. Respondents from teaching hospitals more frequently reported that patient preference is a relevant indication for home care nursing after CEA, EVAR and open AAA repair. 


\section{Discussion}

This survey of Canadian vascular surgeons explored practice patterns and perceptions with regards to the prescription of home care nursing after vascular surgery. There were 4 main findings. First, the availability and routine prescription of home care nursing were higher following open AAA repair and revascularization for PAD than after CEA or EVAR. Second, there was general agreement on procedure-specific indications across all procedures (i.e., surgical site infection, outpatient negative-pressure wound therapy, lymphatic leak and open wound). Third, there was general agreement regarding patient-specific indications across all procedures (i.e., lack of social support, physical frailty and dementia or other cognitive impairment). Lastly, only a few respondents (about 10\%) stated that their practice was informed by local restrictions or standards.

Data on the effect of home care nursing on readmission and health care cost after surgical interventions remains sparse, with a few recent examples relating to transurethral prostatic resection, ${ }^{5}$ joint replacement, ${ }^{6}$ pancreatectomy, ${ }^{7}$ day-case laparoscopic Nissen fundoplication $^{8}$ and hemorrhoidectomy, ${ }^{9}$ short-stay programs after breast surgery ${ }^{10}$ and our group's work on vascular procedures. ${ }^{2,3}$ Use of home care nursing internationally appears to be based on the opinion and training of health care providers. In the United States, eligibility for specifically covered Home Health Services under Medicare is left largely to the discretion of the physician. ${ }^{11}$ In the United Kingdom's National Health Services, eligibility for funded home care support after discharge from the hospital also appears to be coordinated and determined by health care providers. ${ }^{12}$ A 2011 systematic review of home care across Europe identified a paucity of descriptive and comparative studies ${ }^{13}$ and led to increased interest and efforts to better describe home care, namely through the EURHOMAP (Mapping professional care in Europe) collaboration. ${ }^{14}$ Descriptive studies have shown that most eligibility criteria for home care are determined at a national, regional or municipal level for most countries. ${ }^{15}$ There are notable discrepancies among nations in the level of government involvement, informal care conditions and country wealth differences. All of these make transfer of home care policies among countries difficult. ${ }^{16}$ The EURHOMAP project has led efforts to raise awareness about ongoing demographic and social changes that

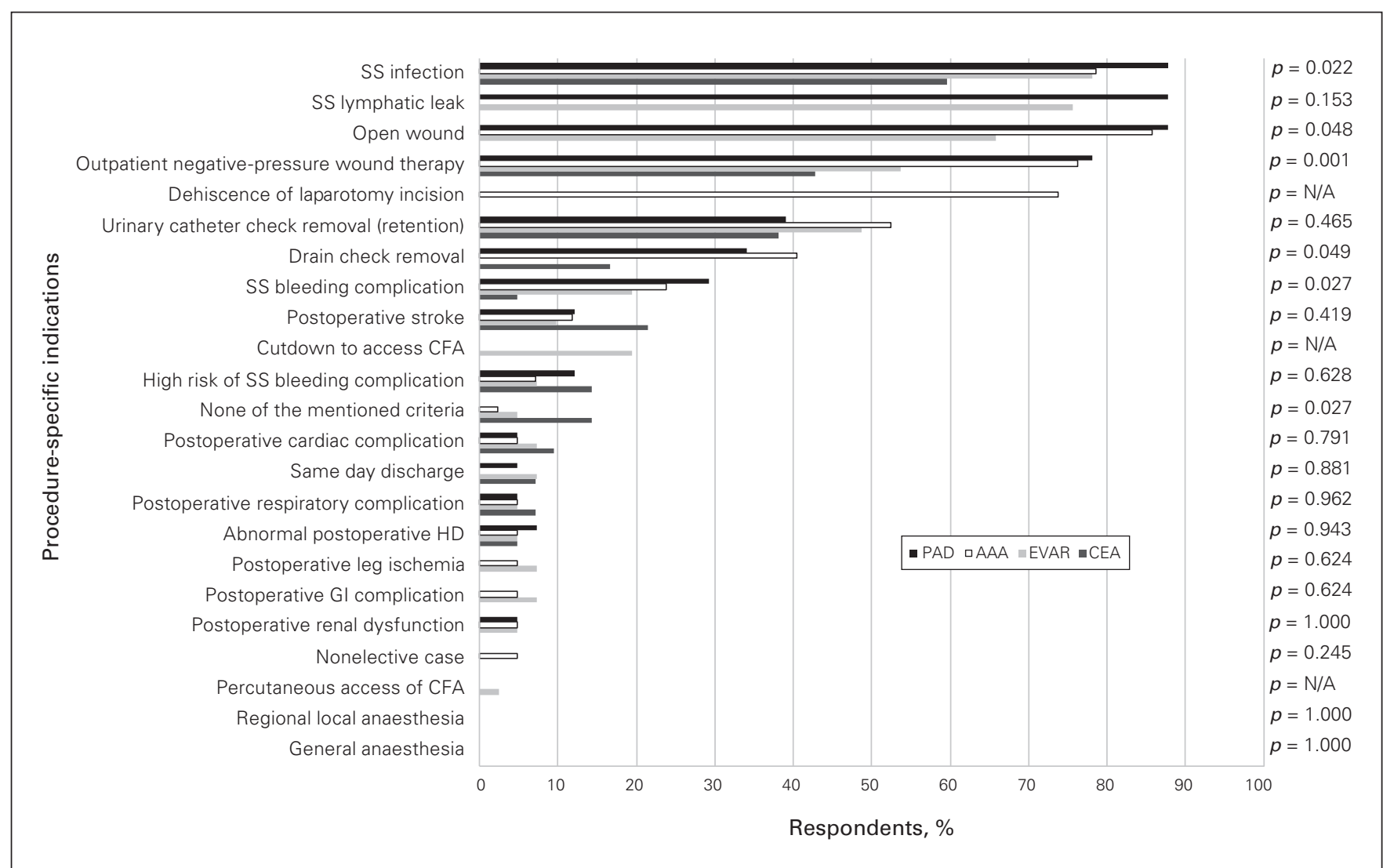

Fig. 1. Procedure-specific indications for discharge with home care nursing after vascular surgery. AAA = open abdominal aortic aneurysm repair; $\mathrm{CEA}=$ carotid endarterectomy; CFA = common femoral artery; EVAR = endovascular abdominal aortic aneurysm repair; $\mathrm{GI}=$ gastrointestinal; $\mathrm{HD}=$ hemodialysis; $\mathrm{N} / \mathrm{A}=$ not applicable; $\mathrm{PAD}=$ open or hybrid lower extremity revascularization for peripheral arterial disease; $\mathrm{SS}=$ surgical site. 


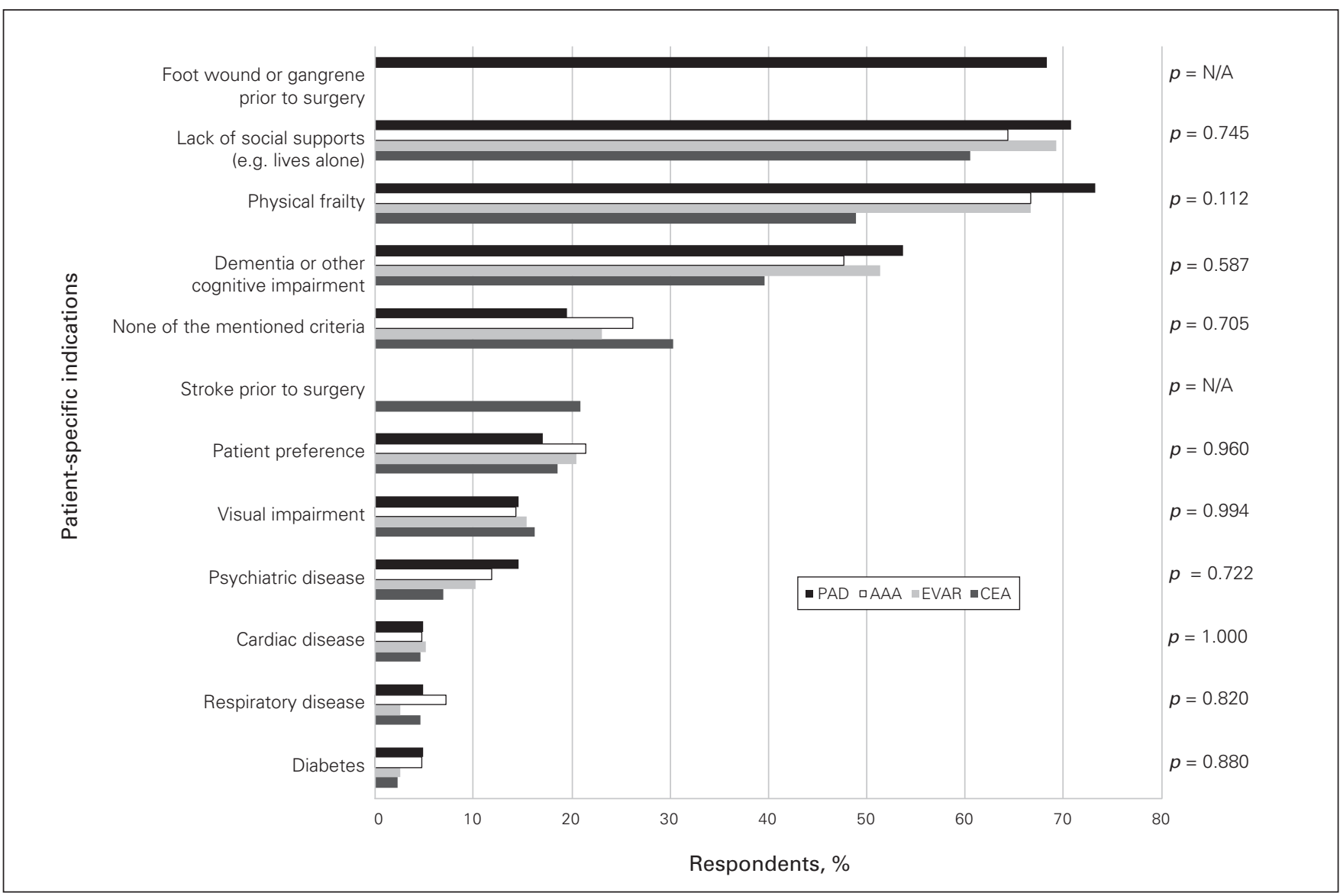

Fig. 2. Patient-specific indications for discharge with home care nursing following vascular surgery. $A A A=0 p e n$ abdominal aortic aneurysm repair; $\mathrm{CEA}=$ carotid endarterectomy; EVAR = endovascular abdominal aortic aneurysm repair; N/A = not applicable; $\mathrm{PAD}=$ open or hybrid lower extremity revascularization for peripheral arterial disease; $\mathrm{SS}=$ surgical site.

increase the demand for home care $^{17}$ and reinforce the importance of establishing clear criteria for home care, given the lack of consensus or guidelines. ${ }^{17}$ Although informative, these studies often fail to address home care eligibility specifically in the context of surgery, nor are they explicit on what constitutes appropriate referral criteria. Our study contributes surgeon-evaluated, relevant indications for discharging a patient with home care nursing after vascular surgery.

Several potential explanations exist for the increased tendency to prescribe home care nursing after open or hybrid revascularization for $\mathrm{PAD}$ and open AAA repair. Patients requiring revascularization frequently present with tissue loss, with rates as high as $84 \% .{ }^{18}$ These require wound care for several weeks to months after revascularization to ensure proper healing and ongoing surveillance for infections. The fact that foot wounds and gangrene before PAD surgery were frequently cited as patient-specific indications for discharge with home care nursing further reinforces this hypothesis. Wound-related complication rates are also higher after surgical revascularization for PAD $(14 \%)^{19}$ and after open AAA repair $(7.1 \%),{ }^{20}$ compared with
$3.4 \%$ after $\mathrm{EVAR}^{21}$ and negligible rates after CEA. ${ }^{22}$ Open AAA repair also has high short-term complication rates ${ }^{20}$ compared with CEA or EVAR..$^{23,24}$ For this reason, physicians may perceive that these patients are more likely to benefit from outpatient evaluation by a nurse before formal follow-up with the surgeon, even if no specific interventions, such as wound care or intravenous antibiotics, are mandated.

The similarities across regions and by hospital teaching status show a relative uniformity in the use of home care nursing across the country. However, in more sparsely populated areas, comprehensive follow-up may be more difficult to access and could result in a lower threshold to routinely prescribe home care nursing. In all settings, however, respondents identified a lack of local standards or guidelines. However, there did appear to be service limitations likely related to funding, as suggested by several comments. This reinforces the idea that evidence-based standards to guide patient selection for home care nursing after vascular surgery are needed to ensure that nursing care is prioritized toward those who benefit the most, especially in the context of scarce home care resources. 


\section{Limitations}

Limitations of this survey should be made explicit. First, although our survey has captured a broad sample of vascular surgeons across Canada, the results may over- or underrepresent certain regions or practice types. Second, although the survey provides a nationwide perspective on home care nursing, discrepancies within regions could not be explored because of the small number of respondents and vascular surgeons currently working in Canada. Finally, the small sample size limits the power for statistical testing of differences across procedure types and regions.

\section{Conclusion}

Most polled members of the Canadian Society for Vascular Surgery had similar prescription patterns for home care nursing after vascular surgery and generally agreed on the potential indications for home care nursing. Although our data suggest general agreement among vascular surgeons, there remains a paucity of evidence to guide patient selection for home care nursing. Future research should focus on how patients benefit from home care nursing services after major vascular interventions. Our results should help define evidence-based standards of practice for home care nursing, which in turn will help best support patient recovery at home.

Affiliations: From the Department of Surgery, University of Toronto, Toronto, Ont. (Jacob-Brassard, Al-Omran, Salata, Hussain, Kayssi, Roche-Nagle); the Li Ka Shing Knowledge Institute of St. Michaels Hospital, Toronto, Ont. (Al-Omran, Salata, Hussain, de Mestral); the Sunnybrook Research Institute of Sunnybrook Health Sciences Centre, Toronto, Ont. (Kayssi); and the Peter Munk Cardiac Center of the University Health Network, Toronto, Ont. (Roche-Nagle).

Competing interests: None declared.

Funding: This work was supported by the Blair Foundation Vascular Surgery Innovation Fund, jointly established with the University of Toronto.

Contributors: J. Jacob-Brassard and C. de Mestral conceived and designed the study. J. Jacob-Brassard acquired the data, which all authors analyzed and interpreted. J. Jacob Brassard and C. de Mestral drafted the manuscript, which all authors critically revised. All authors approved the final version to be published.

Content licence: This is an Open Access article distributed in accordance with the terms of the Creative Commons Attribution (CC BYNC-ND 4.0) licence, which permits use, distribution and reproduction in any medium, provided that the original publication is properly cited, the use is noncommercial (i.e., research or educational use), and no modifications or adaptations are made. See: https://creativecommons. org/licenses/by-nc-nd/4.0/

\section{References}

1. Romagnoli KM, Handler SM, Hochheiser H. Home care: more than just a visiting nurse. BM7 Qual Saf 2013;22:972-4.

2. De Mestral C, Salata K, Hussain MA, et al. Evaluating quality metrics and cost after discharge: a population-based cohort study of value in health care following elective major vascular surgery. Ann Surg 2019;270:378-83.
3. De Mestral C, Kayssi A, Al-Omran M, et al. Home care nursing after elective vascular surgery: an opportunity to reduce emergency department visits and hospital readmission. BMF Qual Saff 2019;28:901-7.

4. Eysenbach G. Improving the quality of Web surveys: the Checklist for Reporting Results of Internet E-Surveys (CHERRIES). 7 Med Internet Res 2004;6:e34.

5. Kaye DR, Syrjamaki J, Ellimoottil C, et al. Use of routine home health care and deviations from an uncomplicated recovery pathway after radical prostatectomy. Urology 2018;112:74-9.

6. Ponzio DY, Park AG, Bhat SB, et al. Can we reduce the utilization of home-visiting nurse services after primary total joint arthroplasty? J Arthroplasty 2016;31:50-3.

7. Sanford DE, Olsen MA, Bommarito KM, et al. Association of discharge home with home health care and 30-day readmission after pancreatectomy. 7 Am Coll Surg 2014;219:875-86.

8. Bailey ME, Garrett WV, Nisar A, et al. Day-case laparoscopic Nissen fundoplication. Br 7 Surg 2003;90:560-2.

9. Hunt L, Luck AJ, Rudkin G, et al. Day-case haemorrhoidectomy. Br 7 Surg 1999;86:255-8.

10. De Kok M, van der Weijden T, Voogd AC, et al. Implementation of a short-stay programme after breast cancer surgery. Br 7 Surg 2010;97:189-94.

11. Home health services coverage. Medicare.gov. Available: www.medicare. gov/coverage/home-health-services (accessed 9 Aug. 2019).

12. Arranging care before you leave hospital. National Health Services; 2018 Available: www.nhs.uk/conditions/social-care-and-support-guide/ care-after-a-hospital-stay/arranging-care-before-you-leave-hospital (accessed 10 Aug. 2019).

13. Genet N, Boerma WG, Kringos DS, et al. Home care in Europe: a systematic literature review. BMC Health Serv Res 2011;11:207.

14. Cabanas $M$, Àngels Ondiviela $M$, Bolibar B et al. EURHOMAP: mapping professional home care in Europe. Int 7 Integr Care 2009;9:E20.

15. Genet N, Boerma W, Kroneman M, et al., editors. Home care across Europe: current structure and future challenges. Copenhagen: World Health Organization, Regional Office for Europe; 2012.

16. Genet N, Kroneman M, Boerma WG. Explaining governmental involvement in home care across Europe: an international comparative study. Health Policy 2013;110:84-93.

17. Tarricone R, Tsouros AD. The solid facts: home care in Europe. Copenhagen: World Health Organization, Regional Office for Europe, 2008.

18. Iida O, Takahara M, Soga Y, et al. Three-year outcomes of surgical versus endovascular revascularization for critical limb ischemia: the SPINACH study (surgical reconstruction versus peripheral intervention in patients with critical limb ischemia). Circ Cardiovasc Interv 2017;10:e005531.

19. Aziz F, Bohr T, Lehman EB. Wound disruption after lower extremity bypass surgery is a predictor of subsequent development of wound infection. Ann Vasc Surg 2017;43:176-87.

20. Zwolak RM, Sidawy AN, Greenberg RK, et al. Lifeline registry of endovascular aneurysm repair: open repair surgical controls in clinical trials. 7 Vasc Surg 2008;48:511-8.

21. Prinssen M, Verhoeven EL, Buth J, et al. A randomized trial comparing conventional and endovascular repair of abdominal aortic aneurysms. N Engl 7 Med 2004;351:1607-18.

22. Gelabert HA, Moore WS. Carotid endarterectomy: current status. Curr Probl Surg 2009;28:181-262.

23. Moore WS, Barnett HJ, Beebe HG et al. Guidelines for carotid endarterectomy. A multidisciplinary consensus statement from the Ad Hoc Committee, American Heart Association. Stroke 1995;26:188-201.

24. Lederle FA, Freischlag JA, Kyriakides TC et al. Outcomes following endovascular vs open repair of abdominal aortic aneurysm: a randomized trial. FAMA 2009;14:1535-42. 